\begin{tabular}{l}
\hline OPEN OA ACCESS Freely available online \\
http://www.banglajol.info/index.php/BJID/index \\
Original Article \\
Bangladesh Journal of Infectious Diseases \\
October 2020, Volume 7, Number Suppl_2, Page S3-SX7 \\
ISSN (Online) 2411-670X \\
ISSN (Print) 2411-4820 DOI: https://doi.org/10.3329/bjid.v7i00.50155
\end{tabular}

\title{
Evidences on Irrational Anti-Microbial Prescribing and Consumption among COVID-19 Positive Patients and Possible Mitigation Strategies: A Descriptive Cross Sectional Study
}

\author{
Monira Parveen ${ }^{1}$, Md. Maruf Ahmed Molla ${ }^{2}$, Mahmuda Yeasmin ${ }^{3}$, Tasnim Nafisa ${ }^{4}$, Arifa Akram \\ Barna $^{5}$, Asish Kumar Ghosh ${ }^{6}$
}

${ }^{1}$ Lecturer, Department of Pharmacology, Dhaka Dental College, Dhaka, Bangladesh; ${ }^{2}$ Medical Officer, Department of Virology, National Institute of Laboratory Medicine \& Referral Center, Dhaka, Bangladesh, ${ }^{3}$ Medical Officer, Department of Virology, National Institute of Laboratory Medicine \& Referral Center, Dhaka, Bangladesh, ${ }^{4}$ Medical Officer, Department of Virology, National Institute of Laboratory Medicine \& Referral Center, Dhaka, Bangladesh, ${ }^{5}$ Assistant Professor, Department of Virology, National Institute of Laboratory Medicine \& Referral Center, Dhaka, Bangladesh, ${ }^{6}$ Lecturer, Department of Virology, Dhaka Medical College, Dhaka, Bangladesh

[Received: 17 August 2020; Accepted: 28 September 2020]

\begin{abstract}
Background: Increased antimicrobial consumption has increased the burden on worsening situation of antimicrobial resistance throughout the world. Objective: The purpose of this study was to assess the practice of irrational antibiotic prescribing and consumption among COVID-19 positive patients of Bangladesh and its possible impact on existing AMR. Methodology: This was a cross-sectional study conducted among SARS-CoV-2 positive patients from a tertiary COVID-19 PCR testing center in Dhaka between $10^{\text {th }}$ July 2020 and $20^{\text {th }}$ July 2020 . A validated questionnaire was used to gather data. Ethical approval was obtained. A total of 100 participants through random sampling was selected. Results: A total of 100 COVID-19 RT-PCR positive patients were participated in this study: $96 \%$ had mild symptoms, fever $(81.0 \%)$ was the most common presenting symptoms, $45.0 \%$ patients did not consult with physicians even after knowing their positive test results and reported self medicating with antibiotics, and $36.0 \%$ were treated with multiple antibiotics and antiviral at a time. Azithromycin (46.0\%), Ivermectin $(22.0 \%)$ and doxycycline $(21.0 \%)$ were the antibiotics most used, which were mainly obtained from local retail pharmacies. Conclusion: Practice of irrational antibiotic prescribing and self medication is relatively high among COVID-19 positive participants. [Bangladesh Journal of Infectious Diseases, October 2020;7(suppl_2):S3-S7]
\end{abstract}

Keyword: COVID-19; anti-microbial resistance; AMR; Bangladesh

Correspondence: Dr. Md. Maruf Ahmed Molla, Medical Officer, Department of Virology, National Institute of Laboratory Medicine and Referral Center, Dhaka, Bangladesh; Email: maruf063@gmail.com; Cell No.: +8801711447858

Conflict of interest: The author has no conflicts of interest to declare.

Funding agency: Authors of this study did not receive funding from any agency.

Contribution to authors: all authors involved in protocol preparation, data collection and literature search up to manuscript writing as well as revision of this manuscript.

How to cite this article: Parveen M, Molla MMA, Yeasmin M, Nafisa T, Barna AA, Ghosh AK. Evidences on Irrational Antimicrobial Prescribing and Consumption among COVID-19 Positive Patients and Possible Mitigation Strategies: A Descriptive Cross Sectional Study. Bangladesh J Infect Dis 2020;7(suppl_2):S3-S7

Copyright: $\odot 2020$. Parveen et al. Published by Bangladesh Journal of Infectious Diseases. This article is published under the Creative Commons CC BY-NC License (https://creativecommons.org/licenses/by-nc/4.0/). This license permits use, distribution and reproduction in any medium, provided the original work is properly cited, and is not used for commercial purposes. 


\section{Introduction}

COVID-19, an ongoing pandemic, has already created immense burden on health and social care system worldwide ${ }^{1-2}$. One of the major issues encountered by physicians and researchers are lack of effective and safe treatment options against COVID-19. Hence, a plethora of anti-microbial agents and biological medicines have already been used either on a trial basis or as a last gasp measure to save patient lives. But, increased prescribing of antimicrobial, without first validating their effectiveness in treating COVID-19 cases, might flare up antimicrobial resistance (AMR) among patients $^{3}$. On the other hand, increased societal awareness towards threats from infectious diseases, rational prescribing of antimicrobial drugs and good sanitary practices during this pandemic may subsequently have beneficial effect on $\mathrm{AMR}^{4}$.

Literature evidences regarding bacterial and fungal co-infection among hospitalized patients are currently lacking, but nevertheless, a significant proportion of them receive multidrug and broad spectrum antibiotic which are classified as critically important antimicrobials (CIA) by WHO, rendering them vulnerable against selection of multidrug resistant (MDR) organisms ${ }^{5}$. Furthermore, in developing countries like Bangladesh and India, where buying antibiotics from pharmacy is a common practice ${ }^{6}$, COVID-19 may further complicate the ongoing fight against AMR.

To prevent high infection rate, antimicrobial soaps and disinfectant cleaners are used widely as the most effective measure against COVID-19 infection, which can also have negative impact on AMR as they contain biocides that are antimicrobials ${ }^{7}$. This exposure of biocidal agents may increase the risk of cross resistance to antibiotics $^{8}$, particularly those that treat Gramnegative bacteria ${ }^{9}$.

There is a well-established national guideline for clinical management of COVID-19 patients in Bangladesh. Without any sign of significant secondary bacterial infection, irrational antibiotic prescribing is prohibited within the national guideline $^{10}$. Despite repeated attempts to avert potential complicated situation like AMR, preliminary reports from national newspaper and hospital records suggest COVID-19 patients with mild symptoms are usually found to be taking selfprescribed antimicrobials such as macrolides (azithromycin), doxycycline, anti-malarial drug (hydroxychloroquine), anti-parasitic (Ivermectin), and even trial drugs such as Favipiravir and
Remdesivir without consulting physicians and completely disregarding their potential harmful side-effects ${ }^{11}$.

This study was conducted to determine the issues of AMR during this era of COVID-19 including, but not limited to, how the ongoing pandemic might complicate the ongoing fight against AMR, evidences of indiscriminate antimicrobial usage among Bangladeshi COVID-19 patients, and how developing countries like Bangladesh should react to fight off this looming threat of AMR.

\section{Methodology}

This was a cross-sectional study conducted among SARS-CoV-2 positive patients from a tertiary COVID-19 PCR testing center in Dhaka between $10^{\text {th }}$ July 2020 and $20^{\text {th }}$ July 2020. In order to evaluate the extent of irrational antimicrobial usage, 100 covid-19 PCR positive patients were selected randomly from a tertiary COVID-19 PCR testing center in Dhaka. Patients aged 18 and above, who were found positive during routine SARS-COV-2 qRT-PCR at least one month prior to interview were included within the study. They were contacted over phone and details regarding their sign-symptoms, drug history and consultation with physician/hospital admission history were sought through a structured and pre-validated questionnaire. Patients were recruited from 10 July to $20 \mathrm{July}$, and proper consent was obtained and anonymity assured. After collection of data, each participant response was cross-checked by individual researcher and made sure there is no discrepancy. Data were analyzed using SPSS software version 21 .

\section{Results}

Among those participants, 96 of them gave accounts of symptoms classified as "mild disease" under the national guideline for COVID-19 clinical management, with most study participants $(n=81)$ citing mild to moderate fever as one of their presenting complaints before opting for SARSCOV-2 PCR. Other notable symptoms included cough/sneezing/runny nose/ sore throat $(n=32)$, headache $(n=19)$, muscle ache $(n=15)$, anosmia $(n=8)$, chest pain/respiratory distress $(n=4)$, diarrhea $(n=3)$, and finally in a number of cases there were no symptoms $(\mathrm{n}=18)$. Participants were asked questions regarding their health service seeking behavior (consultation with a physician) and their drug history. Surprisingly, only 55 participants consulted with a physician after being diagnosed as 
COVID-19 positive, while remaining 45 participants did not consult any physician/ healthcare worker after being diagnosed. Detailed drug history was sought from participants with mild COVID-19 symptoms. A significant number of them $(n=61)$ had one or more anti-microbial in their treatment regimen. Azithromycin was the most frequently prescribed drug $(n=46)$ followed by ivermectin $(\mathrm{n}=22)$, doxycycline $(\mathrm{n}=21)$, and fluoroquinolones such as levofloxacin $(n=6)$, moxifloxacin $(n=4)$, and anti-viral drug such as favipiravir $(n=4)$. Interestingly, only 25 of them had single anti-microbial agent in their treatment regimen with remaining 36 participants taking two or more anti-microbial simultaneously after being diagnosed as COVID-19 positive (Table 1).

Table 1: Data Regarding Disease Severity, Health Service Seeking Behavior, and Antimicrobial Prescription among Study Participants

\begin{tabular}{|c|c|c|}
\hline Variables & Frequency & Percent \\
\hline \multicolumn{3}{|c|}{ Disease Severity $(n=100)$} \\
\hline - $\quad$ Mild & 96 & 96.0 \\
\hline $\begin{array}{l}\text { - Moderate/Severe/ } \\
\text { Critically ill }\end{array}$ & 4 & 4.0 \\
\hline \multicolumn{3}{|c|}{ Presenting Symptom $(\mathrm{n}=100)$} \\
\hline - $\quad$ Fever & 81 & 81.0 \\
\hline $\begin{array}{l}\text { - Cough/ Sneezing/ } \\
\text { Runny nose }\end{array}$ & 32 & 32.0 \\
\hline - Headache & 19 & 19.0 \\
\hline - Muscle ache & 15 & 15.0 \\
\hline $\begin{array}{lll}\text { - } & \text { Chest pain/ } \\
\text { respiratory } & \\
\text { distress } & \\
\end{array}$ & 9 & 9.0 \\
\hline - Anosmia & 8 & 8.0 \\
\hline - Diarrhea & 3 & 3.0 \\
\hline - $\quad$ No symptom & 18 & 18.0 \\
\hline \multicolumn{3}{|c|}{ Health service seeking behavior $(\mathrm{n}=100)$} \\
\hline $\begin{array}{l}\text { Consult with } \\
\text { physician/ Health } \\
\text { care worker }\end{array}$ & 55 & 55.0 \\
\hline - No consultation & 45 & 45.0 \\
\hline \multicolumn{3}{|c|}{ Antimicrobial prescription $(n=61)$} \\
\hline $\begin{array}{ll}\text { - } & \begin{array}{l}\text { Treated with } \\
\text { single agent }\end{array} \\
\end{array}$ & 25 & 25.0 \\
\hline $\begin{array}{l}\text { - Combination of } \\
\text { more than one } \\
\text { antimicrobial }\end{array}$ & 36 & 36.0 \\
\hline \multicolumn{3}{|c|}{ Prescribed Antimicrobial drugs $(\mathrm{n}=61)$} \\
\hline - Azithromycin & 46 & 46.0 \\
\hline - Ivermectin & 22 & 22.0 \\
\hline - Doxycycline & 21 & 21.0 \\
\hline - Levofloxacin & 6 & 6.0 \\
\hline
\end{tabular}

\begin{tabular}{|c|c|c|}
\hline - Moxifloxacin & 4 & 4.0 \\
\hline - $\quad$ Favipiravir & 4 & 4.0 \\
\hline
\end{tabular}

\section{Discussion}

Around 700000 people die each year due to antibiotic resistance. If urgent measures are not taken, by the year 2050 around 10 million people would lose their lives to resistant microbes culminating in a financial loss similar to that of 2008-09 global financial crisis ${ }^{12}$. This projection is applicable for all countries irrespective of financial prowess, but the burden would be felt heavier by low-middle and low income countries including densely populated countries in South Asia and parts of Africa ${ }^{5}$.

Current study findings reveal that participants often indulged themselves with unnecessary and irrational antimicrobial treatment considering most of them $(n=96)$ were suffering from "mild" COVID-19 disease according to national guidelines. Moreover, a significant proportion of them $(n=45)$ did not consult physician prior to starting antimicrobial course, and mostly relied on advices from pharmacists and persuaded by social media propaganda. Hence, the intervention and mitigation strategies should include strict implementation of clinical treatment guidelines of COVID-19 to limit unnecessary antimicrobial usage, appropriate measures to intensify routine surveillance of AMR and restriction of over-the counter (OTC) sales of antimicrobial by law enforcement ${ }^{13}$. Ensuring appropriate antimicrobial in hour of need while avoiding unnecessary or prolonged antimicrobial course should be the principle of antimicrobial prescribing $^{14}$.

Obtaining adequate microbiological evidence of pathogen before prescribing antimicrobial is of paramount importance to overcome this challenge. Unfortunately, this can be time consuming since there is a lack of advanced laboratory facilities within the country, and hence often puts the physician in a dilemma, especially when patient is critically ill and requires urgent intervention. As a result, without proper dosing and indications nearly half of all antimicrobial are being prescribed, which may contribute to the development of resistant pathogens ${ }^{15}$.

In order to overcome this issue, procalcitonin, an important serum biochemical marker can serve as a helpful adjunct to clinical judgment to distinguish between bacterial and viral infection especially in Lower Respiratory Tract Infection (LRTI) and for 
guiding antibiotic therapy as it remains undetectable in healthy individual ${ }^{16}$. Bacterial endotoxins as well as inflammatory cytokines such as TNF, IL-1B, and IL-6 act as a trigger for increased production of procalcitonin ${ }^{17}, 18$. Little is known about correlation between SARS-CoV-2 and serum level of procalcitonin. However, rise of serum procalcitonin level in COVID-19 patients was observed in patients who required hospitalization or ICU admission explaining plausible bacterial coinfection or release of cytokine due to severe inflammatory response ${ }^{19-20}$. In this regard procalcitonin might act as a guiding tool to initiate antibiotic in COVID-19 infected patients or patients presented with symptoms of LRTI during this pandemic.

There should be a clamping down on irrational prescription of anti-microbial without proper advices from clinicians. One possible solution in Bangladeshi context could be introduction of color coded strips of anti-microbial so that people purchasing them from pharmacy might know the potential harms associated with consumption these drugs without proper indication ${ }^{21}$.

Another reason behind anti-microbial resistance is not taking drugs for suggested duration treatment. People usually purchase anti-microbial from pharmacy and as soon as symptoms are alleviated, they stop taking anti-microbial without completing the course. This might be solved with introduction of tightly sealed bottle containing anti-microbial drugs sufficient for a 3, 7, 14 or 21 day course.

Social media platforms may play influential role in educating and raising awareness among antimicrobial prescribers, patients, and the general public on the significance of antibiotics in viral infections. Visual aids such as posters, brochures, and advertisements could be used in the local media as worthwhile intervention strategies. Awareness campaign displaying local surveillance data and sharing real life experience of individuals who have suffered from COVID-19 or any superbug in the past may help create a positive impact within the communities $^{22}$.

Motivating physicians to start communicating with patients about the judicial use of antimicrobial and negative effect of AMR on health and economy might significantly improve the chances of success of such campaign ${ }^{23}$. Besides these, telemedicine could play potential role in this regard. This innovative technology allows physicians to provide critical support to COVID-19 patients as well as routine services to general people including valuable lessons on $\mathrm{AMR}^{24}$.

\section{Conclusion}

The report illustrated the central importance of rational prescribing of anti-microbial during COVID-19 pandemic. It is evident that, Bangladesh, with a fragile health infrastructure, is currently struggling to curb down on overuse of antimicrobial among COVID-19 patients with a significant percentage of them, mostly with mild disease, taking one or more anti-microbial without consultation from physician or health care worker. Suggested mitigation strategies include strict regulation of over the counter (OTC) antimicrobial prescription, testing biochemical marker such as procalcitonin prior to initiation of antimicrobial therapy, introduction of color coded and tightly sealed bottled antimicrobial drugs, massive campaigning on social media, effective utilization of telemedicine and finally, raising awareness among physicians and patients regarding judicial use of antimicrobial. More and extensive researches are recommended in near future to understand the true nature of antimicrobial overuse among Bangladeshi COVID-19 patients. Hence, immediate necessary measures and mitigation strategies should be adopted to curtail the emerging threat of AMR.

\section{References}

1. Zhu N, Zhang D, Wang W, Li X, Yang B, Song J, et al. A novel coronavirus from patients with pneumonia in China, 2019. N Engl J Med. 2020;382(8):727-733.

2. Phelan AL, Katz R, Gostin LO. The novel coronavirus originating in Wuhan, China: challenges for global health governance. JAMA. 2020;323(8):709-710.

3. Rawson TM, Ming D, Ahmad R, Moore LSP, Holmes AH. Antimicrobial use, drug-resistant infections and COVID-19. Nat Rev Microbiol. 2020;18(8):409-410.

4. Rawson TM, Moore LSP, Castro-Sanchez E, Charani E, Davies F, Satta G, et al. COVID-19 and the potential long-term impact on antimicrobial resistance. J Antimicrob Chemother. 2020;75(7):1681-1684.

5. World health organization. Newsroom [Internet]. New York: WHO; 2019. New report calls for urgent action to avert antimicrobial resistance crisis. [Cited on 2020 August 28]. Available from: https://www.who.int/news-room/detail/29-042019-new-report-calls-for-urgent-action-to-avert-antimicrobialresistance-crisis

6. Rawson TM, Moore LS, Zhu N, Ranganathan N, Skolimowska K, Gilchrist M, et al. Bacterial and fungal coinfection in individuals with coronavirus: A rapid review to support COVID-19 antimicrobial prescribing. Clin Infect Dis. 2020 May 2.

7. Saha S, Hossain MT. Evaluation of medicines dispensing pattern of private pharmacies in Rajshahi, Bangladesh. BMC Health Serv Res. 2017;17(1):136.

8. Caselli E. Hygiene: microbial strategies to reduce pathogens and drug resistance in clinical settings. Microb Biotechnol. 2017;10(5):1079-1083. 
9. Kampf G. Biocidal agents used for disinfection can enhance antibiotic resistance in gram-negative species. Antibiotics. 2018;7(4):110.

10. World Health Organization. WHO Health Emergency Dashboard. Last Updated On:7 October 2020. Available from: https://covid19.who.int/ [Retrieved October 5, 2020].

11. National guidelines on clinical management of coronavirus Disease 2019 (COVID-19). Bangladesh: Disease Control Division Directorate General of Health Services Ministry of Health \& Family Welfare Government of the People's Republic of Bangladesh. Version 4.0; March 302020 . Available from: http://www.mohfw.gov.bd/index.php?option=com_docman\&ta sk=doc_download\&gid=22424\&lang=en [Retrieved October 5, 2020].

12. Hossain E. Government, people stockpile drugs touted as coronavirus cure [Internet]. 2020 Mar 28 [cited 2020 Oct 5]. Available from https://www.newagebd.net/article/103272/government-peoplestockpile-drugs-touted-as-coronavirus-cure

13. World Health Organization. Antimicrobial resistance: global report on surveillance. 2014 Apr [cited 2020 Oct 5]. Available from https://www.who.int/antimicrobialresistance/publications/surveillancereport/en/

14. Leekha S, Terrell CL, Edson RS. General principles of antimicrobial therapy. In Mayo Clinic Proceedings. Elsevier; 2011;86(2):156-167.

15. Ahmed I, Rabbi MB, Sultana S. Antibiotic resistance in Bangladesh: A systematic review. Int J Infect Dis. 2019;80:5461.

16. Self WH, Wunderink RG, Jain S, Edwards KM, Grijalva CG, Etiology of Pneumonia in the Community (EPIC) Study Investigators. Procalcitonin as a marker of etiology in adults hospitalized with community-acquired pneumonia.
Clin Infect Dis. 2018;66(10):1640-1641

17. Dandona P, Nix D, Wilson MF, Aljada A, Love J, Assicot M, et al. Procalcitonin increase after endotoxin injection in normal subjects. J Clin Endocrinol Metab. 1994;79(6):1605-1608.

18. Harbarth S, Holeckova K, Froidevaux C, Pittet D, Ricou B, Grau GE, et al. Geneva Sepsis Network. Diagnostic value of procalcitonin, interleukin-6, and interleukin- 8 in critically ill patients admitted with suspected sepsis. Am J Respir Crit Care Med. 2001;164(3):396-402.

19. Conti P, Ronconi G, Caraffa A, Gallenga CE, Ross R, Frydas I, et al. Induction of pro-inflammatory cytokines (IL-1 and IL-6) and lung inflammation by Coronavirus-19 (COVI-19 or SARS-CoV-2): anti-inflammatory strategies. J Biol Regul Homeost Agents. 2020;34(2):327-31.

20. Lippi G, Plebani M. Procalcitonin in patients with severe coronavirus disease 2019 (COVID-19): a meta-analysis. Clin Chim Acta. 2020;505:190-191.

21. Goyal PK, Semwal A, Prakash A, Medhi B. Emerging antimicrobial resistance and newer tools to address the resistance. Indian J Pharmacol. 2019;51(5):291-295.

22. Zowawi HM, Abedalthagafi M, Mar FA, Almalki T, Kutbi AH, Harris-Brown T, et al. The potential role of social media platforms in community awareness of antibiotic use in the gulf cooperation council states: luxury or necessity? J Med Internet Res. 2015;17(10): 233.

23. Local Campaign on Antibiotics Alliance (LOCAAL) study group. Doctors and local media: a synergy for public health information? A controlled trial to evaluate the effects of a multifaceted campaign on antibiotic prescribing [protocol]. BMC Public Health. 2011;11(1):816.

24. Monaghesh E, Hajizadeh A. The role of telehealth during COVID-19 outbreak: A systematic review based on current evidence. BMC Public Health. 2020;20(1):1193 